\title{
Genotyping of Cre-lox Mice and Detection of Tissue-Specific Recombination by Multiplex PCR
}

BioTechniques 31:1156-1162 (November 2001)

\author{
P. Leneuve, R. Zaoui, P. \\ Monget $^{1}$, Y. Le Bouc, and \\ M. Holzenberger \\ Hôpital Saint-Antoine, Paris, \\ and ${ }^{1}$ INRA, Nouzilly, France
}

\section{INTRODUCTION}

Conditional approaches for studies in genetically modified laboratory mice are becoming increasingly common, and large-scale applications are being developed. These approaches are based on DNA recombinase technology, with Cre-lox the most advanced system currently available $(8,14-16)$. Phenotypic analysis is the priority in these studies, requiring that the genotyping and monitoring of the efficiency of tissue- and time course-specific recombination be made as quickly as possible. Southern analysis is often used for these tasks and is widely considered to be the gold standard. However, Southern analysis is time consuming and labor intensive, not always optimal for the detection of subtle mutations such as loxP insertions, and is frequently unsuitable for the simultaneous detection of multiple alleles (e.g., wild-type, floxed, and knockout) and ( $\mathrm{Cre}$ ) transgenes in a single assay. Simultaneous testing for all alleles in a single reaction is both cheaper and more reliable. The reliability of the assay is particularly important when individual mice, depending on genotype, are to be used in long-term studies, costly experiments, or for the breeding of subsequent generations. PCR amplification from various templates, using more than one primer pair in the reaction (multiplexing) (21), may overcome some of the drawbacks of Southern blotting. In addition, multiplex PCR is fast, requires very little sample, and can be designed with flexibility and adapted to almost any target configuration. Unlike Southern analysis, it does not depend on naturally occurring or created restriction enzyme sites. A technique for the detection of $\operatorname{lox} P$ sites in mice has recently been proposed (13). Here, we develop this technique into a strategy for determining Cre-lox genotypes and for quantitatively estimating Cre recombinatory efficiency in target tissues.

\section{MATERIALS AND METHODS}

\section{Animals and Tissue Sampling}

Transgenic mice (genetic background: 129/SvPas, C57B1/6, or FVB) were housed in standard conditions $\left(25^{\circ} \mathrm{C}\right.$, a 12 -h light/dark cycle, with water and food given ad libitum). For PCR, we used 1-3 mg toe or tail biopsy tissue from four-day-old pups. For Southern blotting, 5-mm tail biopsy samples from 10-day-old animals were used. The adult animals were euthanized, and 50mg tissue samples were collected. The samples were either used immediately or stored frozen at $-20^{\circ} \mathrm{C}$ before use.

\section{Genomic PCR}

Lyophilized proteinase $\mathrm{K}$ (Invitrogen, Carlsbad, CA, USA) was dissolved at $10 \mathrm{mg} / \mathrm{mL}$ in $50 \mathrm{mM}$ Tris$\mathrm{HCl}$, pH 8.0, with $5 \mathrm{mM}$ calcium acetate and stored at $4^{\circ} \mathrm{C}$. We added 2 $\mu \mathrm{L}$ stock solution to tail tip or toe biopsy samples that had been previously placed into $200 \mu \mathrm{L}$ GNT-K buffer (12). GNT-K buffer consisted of $10 \mathrm{mM}$ Tris- $\mathrm{HCl}, \mathrm{pH} 8.5,50 \mathrm{mM} \mathrm{KCl}, 1.5 \mathrm{mM}$ $\mathrm{MgCl}_{2}, \quad 0.01 \%$ gelatin, $0.45 \%$ Nonidet $^{\mathrm{TM}}$ P-40 (Sigma, St. Louis, MO, USA), and $0.45 \%$ Tween $^{\circledR} 20$ (Sigma). The samples were digested for no more than $2 \mathrm{~h}$ at $56^{\circ} \mathrm{C}$ on a dry heat block. The samples were then heated at $95^{\circ} \mathrm{C}$ for $15 \mathrm{~min}$ to inactivate proteinase $\mathrm{K}$ 
and were briefly centrifuged at $13000 \times$ $g$ for $1 \mathrm{~min}$. Immediately after centrifugation, $2 \mu \mathrm{L}$ DNA-containing supernatant were transferred to $50-\mu \mathrm{L}$ reactions. For the floxed insulin-like growth factor type I receptor (IGF-IR) locus, the amplification conditions were $94^{\circ} \mathrm{C}$ for a 3-min initial strand separation, 40 cycles at $94^{\circ} \mathrm{C}$ for $45 \mathrm{~s}, 50^{\circ} \mathrm{C}$ for $45 \mathrm{~s}$, $72^{\circ} \mathrm{C}$ for $1 \mathrm{~min}$, and a 7 -min final elongation step at $72^{\circ} \mathrm{C}$. Three oligonucleotides were used to detect wild-type, floxed, and total excised targeted alleles simultaneously. Oligonucleotide 5'-CCATGGGTGTTAAATGTAATGGC-3' was complementary to a seq uence upstream from the left $\operatorname{lox} P$ site (Figure 1), 5'-ATGAATGCTG GTGAGGGTTGTCTT-3' downstream from the right $\operatorname{lox} P$ site and $5^{\prime}$-ATCTTGGAGTGGTTGGGTCTGTTT-3' upstream from the right loxP site. The expected product sizes were 271,327 , and 202 bp for wild-type, floxed, and excised alleles. The oligonucleotides were designed to prevent primer in- compatibility within and between primer sets, and amplification conditions (annealing temperature, elongation time, and primer and magnesium chloride concentrations) were optimized as previously described $(4,17)$. For Cre transgenes, the amplification conditions were as above, except that an annealing temperature of $55^{\circ} \mathrm{C}$ was used. Four oligonucleotides were used to detect Cre and Gabral (endogenous positive control gene) simultaneously. The primers 5'-AACACACACTGG A GGACTGGCTAGG-3' and 5'-CAA TGGTAGGCTCACTCTGGGAGATGATA-3' amplified a 290-bp fragment from the Gabral gene, and the primers 5'-CCTGGAAAATGCTTCTGTCCG$3^{\prime}$ and $5^{\prime}$-CAGGGTGTTATAAGCAA TCCC-3' amplified a 390-bp fragment from the $C r e$ coding region. If loxP mutations and the Cre transgene were to be detected in the same reaction, then we omitted Gabral primers and used the two Cre primers together with the three primers for the targeted floxed lo-

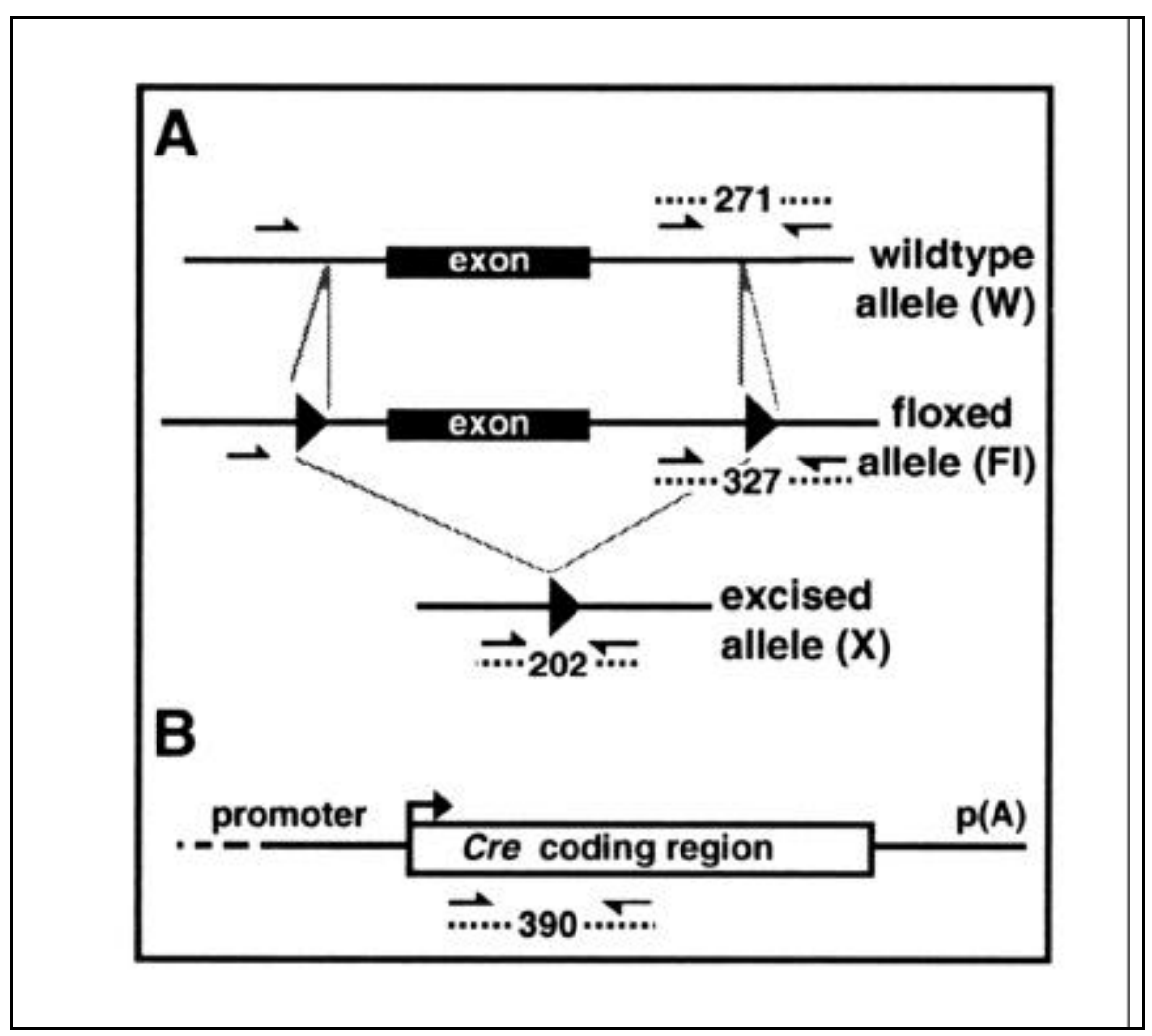

Figure 1. Schematic representation of PCR-amplified loci. (A) Three primers (arrows) were designed to distinguish three related alleles of the IGF-IR gene: wild-type allele (W), floxed allele (Fl), and $\mathrm{Cre}$ lox excised allele (X). LoxP sites are indicated by triangles. The sizes of the amplification products are given in bp. (B) A single pair of Cre primers amplified a 390-bp fragment from the wild-type recombinase coding region present in all $\mathrm{Cre}$ transgenics. cus, using an annealing temperature of $50^{\circ} \mathrm{C}$. Final concentrations in the reaction buffer (Invitrogen) were $200 \mu \mathrm{M}$ each of the four dNTPs, $2 \mathrm{mM} \mathrm{MgCl}$, $0.12 \mu \mathrm{M}$ each primer, and 1.25 U Taq DNA polymerase (Invitrogen). Reaction mixtures were overlaid with mineral oil. The amplification products were separated by electrophoresis on $2 \%$ agarose gels pre-stained with ethidium bromide. As a DNA molecular size marker, we used a 50- and 100-bp DNA ladder. We used a Mastercycler ${ }^{\circledR} 5330$ (Eppendorf Netheler Hinz GmbH, Hamburg, Germany) and custom oligonucleotides (Genset SA, Paris, France).

\section{Southern Blot}

The tissue $(50 \mathrm{mg})$ was digested overnight at $56^{\circ} \mathrm{C}$ with proteinase $\mathrm{K}$, centrifuged, and the supernatant was mixed with an equal volume of isopropanol. The precipitate was washed with $75 \%$ ethanol, dried, and resuspended in $10 \mathrm{mmol}$ Tris-HCl, $\mathrm{pH}$ 8.0. DNA $(8 \mu \mathrm{g})$ was digested with HincII (New England Biolabs, Beverly, MA, USA), subjected to electrophoresis on a $1 \%$ agarose gel, transferred to nylon membranes (Hybond ${ }^{\circledR} \mathrm{N}^{+}$; Amersham Pharmacia Biotech, Orsay, France) by capillary action, and hybridized with a genomic probe that had been radiolabeled using Rediprime ${ }^{\circledR}$ (Amersham Pharmacia Biotech). The probe recognized the 750-bp intronic region of the IGF-IR gene directly upstream from the left loxP site (Figure 1 and Reference $4)$. The membranes were washed twice in $2 \times$ standard saline citrate (SSC) with $0.1 \%$ SDS at room temperature for 15 min and twice in $0.1 \times \mathrm{SSC}$ with $0.1 \%$ $\mathrm{SDS}$ at $65^{\circ} \mathrm{C}$ for $30 \mathrm{~min}$. The membranes were then placed against X-ray film (Curix $^{\text {TM }}$ RP-2 100 NIF; AgfaGevaert, Mortsel, Belgium) for 1-4 days at $-80^{\circ} \mathrm{C}$ with amplifying screens.

\section{Image Analysis}

Allele prevalence was determined from Southern blot autoradiographic exposures and from photographs taken of ethidium bromide-stained PCR analysis gels on a UV-light transilluminator TF-M20 (Fisher Scientific, Illkirch, France). Autoradiographs were digitized using an Arcus $^{\mathrm{TM}}$ peripheral 
(Agfa-Gevaert) and Adobe ${ }^{\circledR}$ Photoshop ${ }^{\circledR}$ software in automatic translucent-linear mode. Opaque photographs were digitized using a Studioscan ${ }^{\mathrm{TM}}$ (Agfa-Gevaert) under the same conditions as above. We used a Macintosh ${ }^{\circledR}$ informatic environment. The unmodified image files were exported to NIH image software version 1.61 (Bethesda, MD, USA), and the bands corresponding to specific alleles were identified, delimited manually, and their mean brightness was measured. Efficient background subtraction was achieved by measuring the levels of brightness in the areas immediately above and below the bands of interest and by subtracting the calculated average background values from the average brightness of the bands of interest. The corrected average brightness of the bands of interest was multiplied with the size of their surface, resulting in the densitometric volume, $\mathrm{V}$, which was defined as the specific signal corresponding to the identified PCR product. The allele prevalence was calculated based on these densitometric volumes (see Figure 4A). For example, in a homozygous floxed mouse that also carried a Cre transgene, the prevalence of the band corresponding to the excised allele expressed in percent was obtained using

$\mathrm{P}_{\mathrm{X}}(\%)=100^{*} \mathrm{~V}_{\mathrm{X}}{ }^{*}\left(\mathrm{~V}_{\mathrm{X}}+\mathrm{V}_{\mathrm{Fl}}\right)^{-1}$

[Eq. 1]

Data were processed using Microsoft $\mathrm{t}^{\circledR}$ Excel $^{\circledR}$, and statistical analysis of the results was performed using Statview ${ }^{\circledR}$ (Abacus Concepts, Berkeley, CA, USA).
RESULTS

\section{Multiplex PCR for Cre-lox Genotyping}

Simultaneous detection of wildtype, floxed, and excised IGF-IR alleles. When genotyping the offspring from crosses between heterozygous floxed mice (Figure 1), we obtained single bands from homozygous floxed and wild-type offspring. Two bands (homozygous floxed and wild-type) were obtained from heterozygous floxed offspring (Figure 2A). Heterozygous knockout mice gave a twoband signal corresponding to the wildtype and excision alleles (Figure 2B). We tested a mouse population harboring floxed and excised alleles (Figure 2C) and obtained a single excised allele band from a homozygous knockout animal (Figure 2C, sample 2, neonatal lethal genotype) and two bands (floxed and excised band) from heterozygous individuals (Figure 2C, samples 3-7). Southern analysis that was performed in parallel confirmed the genotyping results obtained with this method (data not shown). Simple agarose gel electrophoresis of the PCR products was sufficient to determine the genotype. In the optimized conditions used, no interfering nonspecific products were observed, and it was simple to distinguish between mice heterozygous and homozygous for the floxed mutation using this PCR genotyping method. The entire procedure was generally com pleted the day of the biopsy.

Figure 2. Genotyping of Cre-lox mouse populations. (A) A population composed of wild-type, heterozygous, and homozygous floxed mice was PCR genotyped using the two primers flanking the lower loxP site. A single lower band corresponded to the wild-type animals (samples 10 and 12), a two-band pattern corresponded to heterozygotes harboring one wild-type and one floxed allele $(1,2,4-9,11)$, and a single upper band identified homozygous floxed mice (3). (B) A population of wild-type and heterozygous excised mice were tested with three primers. The two-band pattern identified heterozygous knockout mice $(1,3,5)$. (C) Heterozygous compound mice with one knockout and one floxed allele produced the two expected bands (samples 3-7). A homozygous knockout mouse (a genotype lethal for the neonate) produced a single excised band (2). A wild-type sample (1) was added for comparison. (D) A multicopy Cre transgene was detected in a mixed population of heterozygous transgenic $(1-3,6,8)$ and wild-type animals. The lower (Gabral) band served as a positive PCR control, and the upper band corresponded to the Cre transgene. (E) A population of heterozygous and homozygous floxed mice, with and without the Cre transgene, was screened using all five primers shown in Figure 1. As this Cre (CaMKII $\alpha$ $\mathrm{Cr}$ ) was not active in non-brain tissues, no excised allele was observed in toe or tail DNA. The presence of Cre was indicated by the upper band (390 bp). The lower band indicated the presence of the IGF-IR wild-type allele, and the middle band identified the floxed allele. Mice nos. 1 and 13 were the expected Crefflox/flox conditional knockout individuals. (F) EIIa-Cre-positive mice with ubiquitous mosaic loxP recombination were tested with all five primers, showing that target genotype, transgenic status, and somatic recombination can be tested together. Animal nos. 1, 2, 4, and 5 recombined more strongly than nos. 3 and 6. M, DNA molecular size marker.

Detection of Cre transgenes. We tested several different primer pairs and found that the one used here provided the most consistent and reproducible results. Co-amplification of a fragment from the endogenous Gabral gene (as an internal PCR control) gave two bands for heterozygous $\mathrm{Cre}$ transgenes and a single (Gabral) band for Crenegative littermates (Figure 2D). Although $\mathrm{Cre}$ transgenes with copy numbers of one to approximately 20 were tested, we always obtained the characteristic two-band pattern. Including the three presented here, we tested seven different Cre transgenes (and numerous transgenic lines from some of them) with satisfactory results.

Multiplex PCR for the Cre transgene and floxed locus. In simultaneous amplifications of the Cre transgene and the floxed locus, no internal control was needed because all the animals had alleles of the targeted endogenous gene. Thus, in a single test, we determined the allelic status of the floxed gene and the Cre status of the animal (Figure 2E). As could be expected, the generation of multiple bands in a single reaction resulted in the intensity of any given band

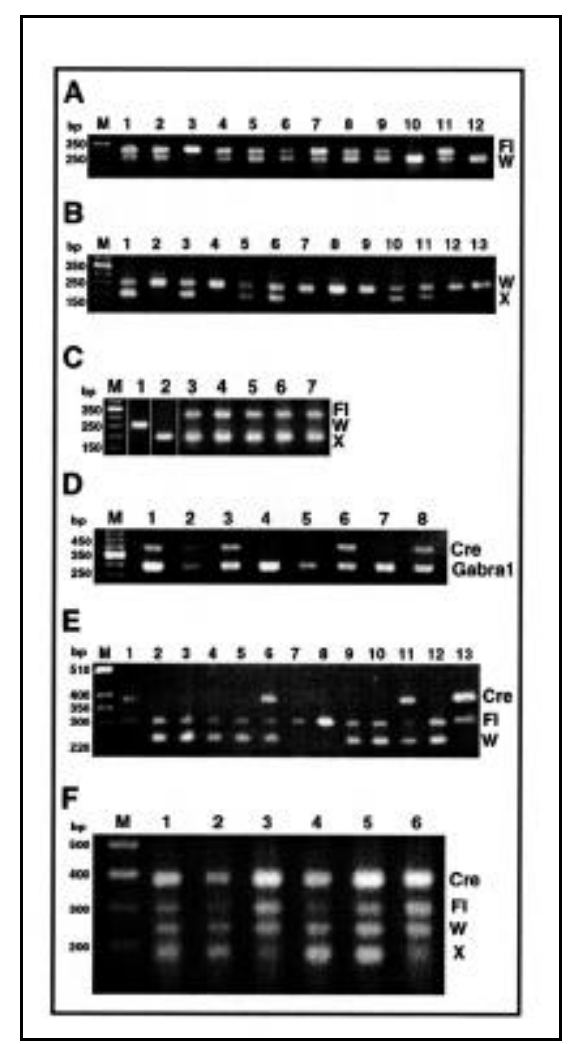


being slightly lower than that shown in Figure 2, A-D. Finally, this test enabled us to detect all three allelic forms of the target gene and Cre in one reaction (Figure 2F) - a very useful possibility when analyzing mosaic Cre-lox mice.

Because the three different PCR products from the IGF-IR gene were of different size $(202,271$, and $327 \mathrm{bp})$ and their amplification involved two upstream and one common downstream primer, we tested whether the ratios between different allele products depended on the PCR cycle number. This was tested in heterozygous IGF-IR flox animals and animals with mosaic Cre-lox recombination. From eight independent reactions taken at increasing cycle num bers, the allelic prevalence was determined as described in the Methods section. Regression analysis showed that the detected ratios between allelic forms (floxed versus wild-type or excised) did not change with cycle number; the mean tendency being close to and not significantly different from zero $(-0.2 \% \pm 0.5 \%$ se Mcycle). Moreover, we determined experimentally the ratio of floxed versus wild-type allele in four heterozygous IGF-IR flox animals (their expected, genetically fixed ratio being 1:1) and found a mean prevalence of $50.1 \% \pm 2.5 \%$ (SEM) for the wildtype allele. We also amplified from one individual bearing one floxed and one excised receptor allele and found a prevalence of $48.6 \% \pm 4.8 \%$ (SEM) for the excised allele. Both values were very close to and not significantly different from the true value. We concluded that the number of PCR cycles, even if the reaction was saturated, did not interfere with the accurate evaluation of allelic composition. In fact, the various alleles behaved as mutual internal PCR controls during the amplification (4).

\section{PCR Analysis of Cre-lox Recombination in Target Tissues}

Tissue-specific Cre-lox excision analyzed by genomic PCR. In three conditional knockout models for which we had previously assayed tissue-specific Cre recombination by Southern blotting, we tested whether the PCR assay would give similar results. In the first model, complete or near complete recombination occurred in specific tissues, the sec- ond model exhibited a partial recombination pattern (we tried to show that PCR reproduced quantitative aspects of Cre-mediated excision), and the third excised in a highly restrictive fashion. The first model involved a Nestin-Cre transgenic mouse that had been shown to induce recombination in all cells of the central nervous system, but not in non-brain tissues $(1,19)$. Our PCR test, using a Nestin-Cre/homozygous flox mouse, showed that the floxed locus was intact in non-brain tissues, but fully recombined in brain tissues (Figure 3A). The second model, using a CaMKII $\alpha$ Cre transgene, efficiently recombined floxed segments in differentiated cortical and hippocampal neurons, but not in glia; lower levels of recombination were observed in other brain regions, and no recombination was detected in nonbrain tissues (20). In this case, genomic PCR showed the expected partial recombination pattern in various regions of the brain and that the floxed locus was intact in other tissues or organs, such as the liver, kidney, muscle, or skin (Figure 3B). The third model used an Inhibin-Cre transgene, which selectively produced $\mathrm{Cre}$ in the gonads from the inhibin $\alpha$-subunit promoter (7; Monget and Holzenberger, unpublished observations). Figure $3 \mathrm{C}$ shows that for males, significant $C r e$ recombination occurred in the testis, but not in any other tissue. However, recombination was not transmitted through the germline because the offspring of such males did not inherit Cre-lox excised alleles.

Quantitative detection of Cre-lox excision events. Analysis of partial Cre recombination is essential in highly restricted, cell type-specific gene inactivation. To validate the multiplex assay, here we compared the PCR and Southern blotting results obtained in conditional knockout experiments using various Cre transgenes. Over the entire range of partial recombinations studied, we found that Southern blot and PCR data correlated very well (Figure 4). The correlation was highly significant for very strong versus very weak recombination, as in the Nestin-Cre model, for example. We also used the EIIaCre transgenic mouse (9) that generates partial and/or mosaic Cre-lox recombination $(6,10)$. In this case, even though the range of partial recombination was 
relatively narrow (e.g., between $30 \%$ and $60 \%$ ) (Figure 4A), the correlation between Southern blot results and PCR-derived data was strong, and the PCR patterns observed reproduced reliably the ratios determined by parallel Southern blotting.

\section{DISCUSSION}

Here, we show that under certain conditions, PCR can replace hybridizationbased techniques. However, the reliability and sensitivity of such assays must be evaluated for each genomic locus amplified. In our hands, PCR genotyping required an initial phase of optimization, essentially to determine the optimal annealing temperatures and the amount of DNA needed to generate a reproducible signal without inhibiting PCR amplification. Any sample for which the first attempt at amplification was unsuccessful was subjected to a second PCR, using variable amounts of DNA input. If am plification was again unsuccessful, then a second biopsy was performed, which generally solved the problem.

Most importantly, the speed of PCR analysis results in major changes in the management of transgenic Cre-lox pro-

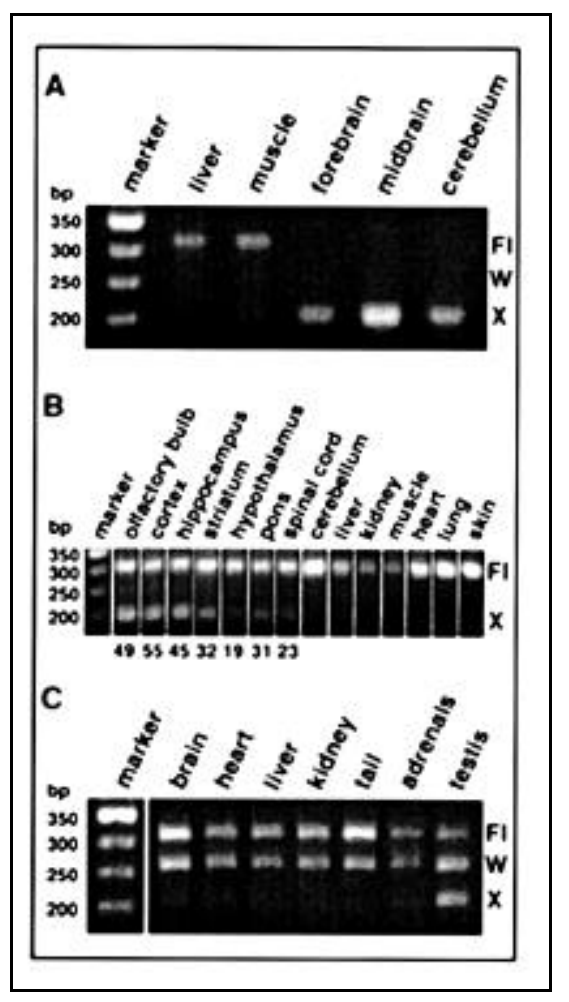

jects. If PCR is used systematically, then important decisions can be made quicker. Animal breeding, in particular, can be immediately continued if too few animals of the desired genotypes have been obtained, and breeding can be stopped earlier when sufficient animals of the desired genotype have been identified. Genotyping on postnatal Day 4 makes the early selection of offspring possible so that if not all genotypes are required (e.g., as negative controls), the litters may be reduced and recomposed from Day 5 onwards, facilitating the recycling of mothers for subsequent breeding. Genotyping at birth is possible using this method, but identification (tattooing) of the new borns is problematic. We found that toe clipping on Day 4 was a safe way to obtain biopsy material for DNA extraction and to permanently identify the animals at the same time.

The proposed protocol ultimately reduces the costs of animal housing and care, thereby rendering Cre-lox projects less time- and labor-intensive. The PCR assay does not require the handling of radioactive materials so that this method is less hazardous than Southern analysis. PCR is easy to modify for use in direct quantification, using fluorochromes and phophorimager technology. A major advantage of PCR genotyping is that only small samples are required, which opens up many other new possibilities. Moreover, the fact that semiquantitative analysis of Cre-lox recombination can rapidly be obtained from tissue biopsies creates new perspectives for the study of Cre-lox animal models, including novel solutions for the analysis of newly established tissue-specific Cre transgenic lines. As demonstrated here for CaMKII $\alpha$-Cre/flox animals, PCR analysis of Cre-lox recombination can be used for in situ Cre-lox recombination detection in microdissected tissue samples. In our hands, $0.5 \mathrm{mg}$ samples still yielded reproducible results, and amplification from microgram amounts of tissue was possible. This constitutes an important advantage over Southern analysis, especially because an increasing number of Cre-lox approaches produce gene excision patterns restricted to minute anatomical regions (e.g., specific areas of the nervous system, small endocrine glands, etc.). To exploit the high sensitivity of PCR for the detection of Cre-lox recombination in a rare population of cells within an organ, for exam ple, or for the detection of incomplete recombination caused by variegated expression of Cre, one needs to perform additional PCR amplifications using only the primer pair that detects the excised allele. We showed that the routine PCR assay can detect as little as one recombined among $10^{3}$ non-recombined alleles, which is a noticeable increase in sensitivity compared to Southern blot.

We also used multiplex PCR to genotype transgenic mice from DNA extracted from hair follicles (18), which is the method of choice for DNA extraction if already identified animals have to be genotyped again and the original DNA sample is no longer available. PCR genotyping will also be the method of choice if automation is required. The use of fluorescent primers and on-line analysis with systems such as TaqMan ${ }^{\circledR}$ (Applied Biosystems, Foster City, CA, USA) may also overcome the time-consuming handling of numerous samples. Finally, other laboratories have recently begun to use Cre-lox PCR genotyping $(2,3,11)$, indicating that this approach is gaining acceptance and may become an alternative to Southern and dot blot analysis in the near future.

Figure 3. Representative examples of tissue-specific Cre recombinations analyzed by PCR in three different Cre-lox models. (A) The Nestin-Cre/homozygous floxed mouse had no recombination in nonbrain tissues such as liver or muscle, but showed complete excision of floxed segments from all regions of the brain tested. Identical patterns were obtained from two other mice. (B) PCR analysis of a CaMKII $\alpha$ $\mathrm{Cre}$ /homozygous floxed mouse showed the expected Cre-mediated excision pattern, with strong recombination in hippocampus, cerebral cortex, and olfactory bulb, some recombination in the striatum, hypothalamic and pontine regions, and the spinal cord, but no detectable recombination in the cerebellum or non-brain tissues. Percent recombination measured from these samples is given below the corresponding lanes. Samples were obtained by scraping 30- $\mu$ m-thick unfixed frozen tissue sections (previously dried on clean glass slides) under a binocular magnifier. Similar profiles were obtained from three other mice. (C) An Inhibin-Cre/heterozygous floxed male displayed, as expected, efficient, but not total excision of the floxed genomic segments from the testis. Very little recombination occurred in other tissues (e.g., adrenal glands or brain). Identical patterns were obtained from five other Inhibin-Cre/heterozygous floxed mice. 


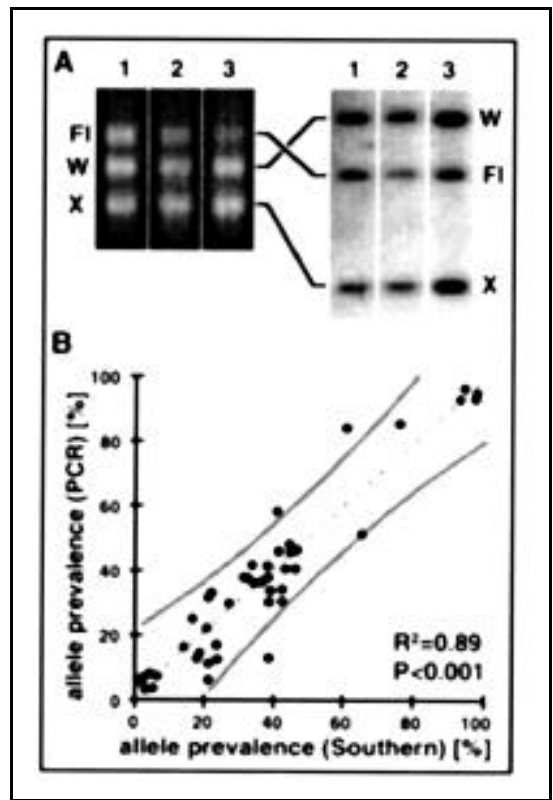

Figure 4. Comparison of PCR results and Southern analysis. (A) Representative examples of PCR-amplified (left) and Southern blot-analyzed (right) partial Cre recombination patterns from three mosaic mice (all EIIa-Cre/flox) (6). PCR and Southern bands that represent the same alleles are connected by lines. (B) Comparison of a larger number of samples from EIIa-Cre/flox, Nestin-Cre/flox, and Inhibin-Cre/flox. Allele prevalence was determined from the relative band intensities measured from Southern blot autoradiographs and photographs taken from ethidium bromide-stained gels. Results obtained using PCR correlated strongly with Southern blot results from the same individuals $(n=44)$.

\section{CONCLUSION}

PCR genotyping of experimental animals is reliable and reproducible if the appropriate controls are included and robust protocols are used. Moreover, it can be a fast and reliable alternative to Southern and dot blotting in Cre-lox conditional gene targeting. Single-tube PCR assays help to reduce errors in genotyping, and same-day results make significant reorganization of animal breeding and housing possible. The detection of tissue-specific Cre-lox recombination patterns may be useful in the screening of newly established Cre transgenic lines and in the analysis of Cre-lox phenotypes.

\section{ACKNOWLEDGMENTS}

Cre and Gabral primers were kindly supplied by Uwe Rudolph (Eidgenös- sisch Technische Hochschule, Zürich, Switzerland). M.H. received a Novo Nordisk Fellowship. The Ministère de l'Education Nationale, Recherche et Technologie-Instituts Fédératifs de Recherche 1999, the Association Française contre les Myopathies, and the University of Paris VI (Faculté SaintAntoine) sponsored this work. Cre transgenic mice were kindly provided by Heiner Westphal (EIIa-Cre), Rüdiger Klein (Nestin-Cre), and François Tronche (CaMKII $\alpha-C r e)$. We wish to thank Julie Sappa for language revision.

\section{REFERENCES}

1.Brüning, J.C., D. Gautam, D.J. Burks, J. Gillette, M. Schubert, P.C. Orban, R. Klein, W. Krone et al. 2000. Role of brain insulin receptor in control of body weight and reproduction. Science 289:2122-2125.

2.de Vries, W.N., L.T. Binns, K.S. Fancher, J. Dean, R. Moore, R. Kemler, and B.B. Knowles. 2000. Expression of Cre recombinase in mouse oocytes: a means to study maternal effect genes. Genesis 26:110-112.

3.Gerber, H.P., K.J. Hillan, A.M. Ryan, J. Kowalski, G.A. Keller, L. Rangell, B.D. Wright, F. Radtke et al. 1999. VEGF is required for growth and survival in neonatal mice. Development 126:1149-1159.

4.Holzenberger, M., S.A. Levi-Minzi, C.P. Herzog, S.B. Deak, L. Robert, and C.D. Boyd. 1993. Quantitation of tropoelastin mRNA and assessment of alternative splicing in human skin fibroblasts by reverse transcriptase-polymerase chain reaction. PCR Meth. Appl. 3:107-114

5.Holzenberger, M., P. Leneuve, G. Hamard, B. Ducos, L. Perin, M. Binoux, and Y. Le Bouc. 2000. A targeted partial invalidation of the insulin-like growth factor I receptor gene in mice causes a postnatal growth deficit. Endocrinol. 141:2557-2566.

6.Holzenberger, M., C. Lenzner, P. Leneuve, R. Zaoui, G. Hamard, S. Vaulont, and Y. Le Bouc. 2000. Cre-mediated germ-line mosaicism: a method allowing rapid generation of several alleles of a target gene. Nucleic Acids Res. 28:e92.

7.Hsu, S.Y., R.J. Lai, D. Nanuel, and A.J. Hsueh. 1995. Different 5'-flanking regions of the inhibin- $\alpha$ gene target transgenes to the gonad and adrenal in an age-dependent manner in transgenic mice. Endocrinol. 136:5577-5586.

8. Kühn, R., F. Schwenk, M. Aguet, and K. Rajewsky. 1995. Inducible gene targeting in mice. Science 269:1427-1429.

9.Lakso, M., J.G. Pichel, J.R. Gorman, B. Sauer, Y. Okamoto, E. Lee, F.W. Alt, and H. Westphal. 1996. Efficient in vivo manipulation of mouse genomic sequences at the zygote stage. Proc. Natl Acad. Sci. USA 93:58605865.

10.Liu, J.L., A. Grinberg, H. Westphal, B. Sauer, D. Accili, M. Karas, and D. LeRoith.
1998. Insulin-like growth factor-I affects perinatal lethality and postnatal development in a gene dosage-dependent manner: manipulation using the Cre/loxP system in transgenic mice. Mol. Endocrinol. 12:1452-1462.

11.Maddison, L.A., H. Nahm, F. DeMayo, and N.M. Greenberg. 2000. Prostate-specific expression of Cre recombinase in transgenic mice. Genesis 26:154-156.

12.Malumbres, M., R. Mangues, N. Ferrer, S. Lu, and A. Pellicer. 1997. Isolation of high molecular weight DNA for reliable genotyping of transgenic mice. BioTechniques 22:11141119.

13.Mantamadiotis, T., S. Taraviras, F. Tronche, and G. Schütz. 1998. PCR-based strategy for genotyping mice and ES cells harboring loxP sites. BioTechniques 25:968-972.

14.Marth, J.D. 1996. Recent advances in gene mutagenesis by site-directed recombination. $\mathrm{J}$. Clin. Invest. 97:1999-2002.

15.Müiller, U. 1999. Ten years of gene targeting: targeted mouse mutants, from vector design to phenotype analysis. Mech. Dev. 82:3-21.

16.Nagy, A. 2000. Cre recombinase: the universal reagent for genome tailoring. Genesis 26:99109.

17.Rychlik, W. and R.E. Rhoads. 1989. A com puter program for choosing optimal oligonucleotides for filter hybridization, sequencing and in vitro amplification of DNA. Nucleic Acids Res. 17:8543-8551.

18.Schmitteckert, E.M., C.M. Prokop, and H.J. Hedrich. 1999. DNA detection in hair of transgenic mice - a simple technique minimizing the distress on the animals. Lab. Anim. 33:385-389.

19.Tronche, F., C. Kellendonk, O. Kretz, P. Gass, K. Anlag, P.C. Orban, R. Bock, R. Klein et al. 1999. Disruption of the glucocorticoid receptor gene in the nervous system results in reduced anxiety. Nat. Genet. 23:99103.

20.Tsien, J.Z., D.F. Chen, D. Gerber, C. Tom, E.H. Mercer, D.J. Anderson, M. Mayford, E.R. Kandel et al. 1996. Subregion- and cell type-restricted gene knockout in mouse brain. Cell 87:1317-1326.

21.Zarlenga, D.S., M.B. Chute, A. Martin, and C.M. Kapel. 1999. A multiplex PCR for unequivocal differentiation of all encapsulated and non-encapsulated genotypes of Trichinella. Int. J. Parasitol. 29:1859-1867.

Received 11 December 2000; accepted 2 May 2001.

Address correspondence to:

Dr. Martin Holzenberger

INSERM U515

Hôpital Saint-Antoine

184 rue du Faubourg Saint-Antoine

F-75571 Paris Cedex 12, France

e-mail: holzenberger@st-antoine.inserm.fr

For reprints of this or any other article, contact Reprints@BioTechniques.com 